\title{
Negative Regulation of Myeloid Cell Activation
}

National Cancer Institute

\section{Source}

National Cancer Institute. Negative Regulation of Myeloid Cell Activation. NCI Thesaurus. Code C40850.

Myeloid Cell Suppression involves interference with, or restraint of, the production and activity of myeloid cells. 